\title{
A consulta ginecológica na adolescência sob a ótica dos ginecologistas e das adolescentes
}

\author{
Gynecological consultation in teens under the view of \\ gynecologists and adolescents
}

Resumo de Tese

Palavras-chave

Adolescência

Anticoncepção

Consulta médica

Sexualidade

Keywords

Adolescence

Anticonception

Medical consultation

Gynecology
Tese apresentada para obtenção do título de Doutora aoPrograma de Pós-graduação em Ciências Médicas, da Universidade do Estado do Rio de Janeiro, em 17 de fevereiro de 2011.

OBJETIVO: avaliar a consulta ginecológica prestada ao público adolescente sob a ótica de médicos e adolescentes. MÉTODO: realizou-se estudo de corte transversal através de questionário estruturado aplicado a 191 ginecologistas filiados à SGORJ e a 418 estudantes do ensino médio de escolas estadual, federal e privada da cidade do Rio de Janeiro. Os médicos responderam sobre dados pessoais, qualificação, condutas e a necessidade de capacitação para o atendimento de adolescentes. As colegiais questionaram-se aspectos sócio-demográficos, comportamento sexual e avaliação da consulta. Na análise dos dados utilizaram-se o teste quiquadrado e o t de student. RESULTADOS: não houve diferenças significativas entre escolares das instituições privada e pública federal que, porém, apresentaram características distintas quando comparadas às estudantes estaduais. Estas eram predominantemente da raça negra, com responsáveis de menor escolaridade e tinham piores condições de moradia. Apesar do maior número de parceiros, gestações, abortamentos e histórico de violência sexual, foram à consulta ginecológica em idade mais tardia, devido à dificuldade de acesso a serviços de saúde sexual e reprodutiva. Os três grupos manifestaram, em comum, o desejo de que o profissional investisse mais tempo, paciência e disponibilidade neste atendimento. Quanto aos profissionais, verificou-se que os mais jovens e as do sexo feminino apresentaram atitudes menos conservadoras na conduta médica. Estes informaram a maior duração da consulta como o principal obstáculo para este atendimento e ressaltaram a importância de treinamento específico e da realização rotineira do exame colpocitológico. CONCLUSÃO: concluiuse que há necessidade de criação de estratégias que facilitem o acesso e a adesão deste grupo etário à rotina preventiva ginecológica e à capacitação profissional específica. 